\title{
Pain Intensity and Its Association with Negative Mood States in Patients with Spinal Cord Injury
}

\author{
Dianah Rodrigues • Yvonne Tran • Nirupama Wijesuriya • \\ Rebecca Guest $\cdot$ James Middleton $\cdot$ Ashley Craig
}

To view enhanced content go to www.paintherapy-open.com Received: August 8, 2013 / Published online: October 12, 2013

(c) The Author(s) 2013. This article is published with open access at Springerlink.com

\begin{abstract}
Introduction: Chronic and persistent pain is a prevalent and debilitating secondary condition in patients with a neurological injury such as spinal cord injury (SCI). Patients with SCI have an increased risk of developing other co-morbid conditions such as elevated negative mood states. Arguably, the presence of chronic pain would act to intensify the chances of developing negative mood states as opposed to resilient mental states. The objective of this research was to investigate the association
\end{abstract}

D. Rodrigues · Y. Tran · N. Wijesuriya - R. Guest . J. Middleton · A. Craig ( $\varangle)$

Rehabilitation Studies Unit, Sydney Medical

School-Northern, The University of Sydney,

PO Box 6, Ryde, NSW 1680, Australia

e-mail: a.craig@sydney.edu.au

Y. Tran

Key University Centre for Health Technologies, University of Technology, Broadway, Sydney,

NSW 2007, Australia

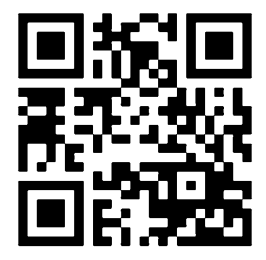

Enhanced content for this article is available on the journal web site: www.paintherapy-open.com between pain intensity and levels of negative mood states in adult patients with SCI.

Methods: Participants included 107 adults with SCI living in the community who completed an assessment regimen in a relaxed environment. Mean pain intensity over a period of 1 week and the Profile of Mood States, a validated psychometric measure of mood states (anxiety, depressed mood, anger, vigor, fatigue, confusion and total negative mood score) were used to determine associations between pain intensity and mood states. The sample was divided into a low pain intensity sub-group $(<4$ where $0=$ no pain; $10=$ worst pain imaginable) and a clinically significant or high pain intensity subgroup $(\geq 4)$, allowing negative mood to be compared between the sub-groups.

Results: Mean age was 47.1 years, and $87 \%$ of the sample was male. Clinically significant pain intensity over the week prior to assessment was found in $52 \%$ of the 107 participants. The high pain intensity sub-group was found to have significantly elevated anxiety, depressed mood, anger, fatigue, confusion and significantly reduced vigor.

Conclusion: These results provide further evidence that patients with SCI experience 
clinically elevated negative mood states if they have intense levels of pain over extended periods of time. In contrast, patients without intense pain have mood states similar to those in the able-bodied community. Implications for the treatment of SCI are discussed.

Keywords: Anxiety; Depressed mood; Negative mood states; Pain intensity; Profile of Mood States; Spinal cord injury

\section{INTRODUCTION}

Spinal cord injury (SCI) is a neurological disorder in which the spinal cord is severely bruised, lacerated, or severed as a result of disease or traumatic injury. While the prevalence of SCI is low, it is a very traumatic and debilitating condition that has ongoing negative impacts on quality of life $[1,2]$. Severe damage to the cord results in loss of sensation and paralysis of voluntary muscles, leading to substantially reduced mobility, increased dependence in activities of daily living, lowered vocational capacity, as well as respiratory, cardiovascular, urinary, gastrointestinal and reproductive system complications [1]. Secondary conditions, such as chronic pain, and psychological morbidity, such as depression, are prevalent and contribute to diminished well-being [3-9]. While the majority of adults with SCI adjust well in the long-term, up to $40 \%$ have an increased risk of depressed mood and clinically elevated levels of anxiety [6]. It has also been estimated that up to $90 \%$ of patients with SCI will experience chronic pain, and for approximately $50 \%$ of these, the pain will be distressing [9-11]. These prevalence rates highlight the need for careful screening of SCI patients for levels of chronic pain and mood states, especially as they come to the end of their inpatient rehabilitation and are about to be discharged into the community. Arguably, if those at risk of clinically significant levels of chronic pain and depressed mood were offered treatment to target these conditions, then adjustment rates would likely improve substantially.

Chronic pain is associated with elevated levels of depressed mood and anxiety [4, 9, $10,12]$. For example, it has been shown that chronic pain is strongly associated with levels of negative mood such that increased pain is associated with increased negative mood and vice versa [10]. Furthermore, chronic pain is associated with a reduction in quality of life [9], and post-traumatic stress disorder is associated with increased chronic pain [12]. The aim of this research was to study the relationship between pain intensity and a range of negative mood states. It was hypothesized that increased pain intensity would be associated with elevated negative mood states such as depressed mood and anxiety, but also with negative mood states such as anger, confusion, reduced vigor and fatigue.

\section{MATERIALS AND METHODS}

\section{Study Participants}

Patients (aged $\geq 18$ years and $<75$ years old) with a SCI and living in the community were eligible for inclusion in the study. Participants were enrolled into the study from a SCI rehabilitation unit $(n=32)$ or via community contacts including through SCI self-help groups or by advertising in SCI community group newsletters. All patients were required to speak and understand instructions in English. All procedures followed were in accordance with the ethical standards of the responsible 
committee on human experimentation (institutional and national) and with the Helsinki Declaration of 1975, as revised in 2000 and 2008. Informed consent was obtained from all patients included in the study. This article does not contain findings from treatment-based clinical intervention studies.

\section{Measures}

To enhance validity, all assessment was conducted during an interview in a relaxed environment that included either the participant's home or a dedicated room in a research institution. In this interview, participants were asked to rate their average pain intensity over the past week using a numerical rating scale from 0 to $10[19,20]$, where $0=$ "no pain" and $10=$ "pain as bad as can be imagined." Numerical pain rating scales of this variety have been shown to have acceptable test-retest reliability and validity in terms of associations with other pain measures and treatments $[13,14]$. A score of 4 or above on this type of pain intensity numerical rating scale is considered indicative of clinically significant pain [15].

The Profile of Mood States (POMS) was used to measure negative mood [16]. The POMS is a 65-item, 5-point Likert-type measure of six mood state domains. A total POMS score can also be calculated according to the algorithm found in the POMS Manual [16]. The six domains include tension (or anxiety), depressed mood, anger, vigor, fatigue and confusion. High scores suggest elevated negative mood, except for vigor where high scores suggest satisfactory vigor. Participants are asked to rate themselves ( $0=$ Not at all and $4=$ Extremely) on descriptors such as "unhappy", "gloomy", "miserable", "panicky", "tense", "nervous", 'tired', and 'lively'. The POMS has been shown to have acceptable test-retest reliability and validity, as well as high internal reliability, with demonstrated Cronbach's alpha coefficients approaching 0.90 or above [16].

\section{Statistical Analysis}

Descriptive statistics and frequencies were calculated for the demographic and injury variables. One-sample $t$ tests were used to compare POMS domain scores with POMS community and psychiatric outpatient norms [16]. The relationship between pain intensity and negative mood states was determined by dichotomizing the SCI group into low $(<4)$ and high $(\geq 4)$ pain intensity sub-groups based on the definition of clinically significant pain described previously. Post hoc statistical power analyses $(1-\beta)$ were calculated and reported. MANOVA was performed to determine whether significant differences existed between the two sub-groups across POMS domains. This was followed by a series of one-way ANOVAs to determine where differences occurred as a function of low versus high pain intensity. Eta-squared $\left(\eta^{2}\right)$ values were provided as an indication of the size of the difference between the two samples. An $\eta^{2}$ of approximately 0.03 was considered a small difference, 0.13 a medium difference and $>0.2$ considered a large and substantial difference [17]. All analyses were performed using Statistica Software (Version 9, Statsoft).

\section{RESULTS}

\section{Patients}

A total of 107 patients participated in the study. Mean age (SD) was $47.1( \pm 14)$ years (range $18-74) ; 87 \%$ of patients were male ( $n=93), 61 \%$ $(n=65)$ had paraplegia, and 39\% $(n=42)$ had 
tetraplegia. Forty-nine percent $(n=53)$ of patients were assessed by a medical specialist as having an incomplete lesion, with the remaining participants having complete lesions $(51 \%, n=54)$. The mean age at injury was $32.4( \pm 16.5)$ years, mean time since the injury was $14.7( \pm 13.9)$ years and the mean number of years of education was $13.6( \pm 2.3)$ years. Most of the participants $(73 \%, n=78)$ were on medications, most commonly analgesics, anti-spasmodics, hypnotics and anti-depressants.

Mean (SD) pain intensity score was 3.7 $(\mathrm{SD}=2.9 ; \quad 95 \% \quad \mathrm{CI} \quad 3.1-4.2)$. Of the 107 participants, $23(21.5 \%)$ reported no pain on the day of assessment, suggesting a pain frequency of $78.5 \%$. Table 1 shows POMS domain scores for the sample, and for POMS community and POMS psychiatric outpatient norms [16]. Compared to the POMS community norm sample, the SCI sample had significantly elevated depressed mood, lower vigor, and elevated total POMS scores. In contrast, the SCI sample had significantly lower negative mood states and higher vigor compared to the POMS psychiatric sample norms.

After splitting the SCI sample into subgroups, $48 \% \quad(n=51)$ of patients were categorized in the low pain intensity $(<4)$ group and $52 \%(n=56)$ of patients in the high pain intensity $(\geq 4)$ group. The low pain intensity sub-group had a mean pain intensity score of 1.1 ( $\mathrm{SD}=1.1 ; 95 \%$ CI 0.82-1.4) while the high pain intensity sub-group had an elevated mean pain intensity score of 6.0 $(\mathrm{SD}=2.0 ; 95 \%$ CI 5.4-6.5). The high pain intensity sub-group had significantly higher levels of negative mood states and reduced vigor compared to the low pain intensity subgroup (Wilks $\lambda=0.84, \quad F_{7,99}=2.6, \quad p<0.05$, $\eta^{2}=0.16$, power $=87 \%$ ). Table 2 shows mean POMS domain scores for the two pain intensity sub-groups, as well as results of the one-way ANOVA tests, effect sizes $\left(\eta^{2}\right)$ and post hoc statistical power $(1-\beta)$. Table 2 shows that effect sizes for differences between the subgroups were moderate to large, that is, in comparison, the high pain intensity sub-group

Table 1 POMS domain scores for the SCI sample $(N=107)$, and POMS domain score norms for adult community and outpatient psychiatric samples [16]

\begin{tabular}{|c|c|c|c|c|c|}
\hline \multirow{2}{*}{$\begin{array}{l}\text { POMS } \\
\text { domains }\end{array}$} & \multicolumn{2}{|l|}{ Mean (SD) } & \multirow{2}{*}{$\begin{array}{l}t \text { test } \\
\text { value }\end{array}$} & \multirow{2}{*}{$\begin{array}{l}\text { POMS psychiatric } \\
\text { outpatients Mean (SD) }\end{array}$} & \multirow{2}{*}{$\begin{array}{l}t \text { test } \\
\text { value }\end{array}$} \\
\hline & $\begin{array}{l}\text { SCI } \\
\text { sample }\end{array}$ & $\begin{array}{l}\text { POMS } \\
\text { community }\end{array}$ & & & \\
\hline Tension & $7.4(6.5)$ & $7.7(5.9)$ & ns & $19.9(8.9)$ & $-19.9^{* *}$ \\
\hline Depressed mood & $10.3(11.4)$ & $8.0(9.3)$ & $2.1^{*}$ & $26.0(15.8)$ & $-14.1^{* *}$ \\
\hline Anger & $8.7(8.8)$ & $7.6(7.4)$ & $\mathrm{ns}$ & $14.4(11.1)$ & $-6.7^{* *}$ \\
\hline Vigor & $16.6(6.1)$ & $19.3(6.7)$ & $-4.5^{* *}$ & $10.0(6.5)$ & $11.2^{* *}$ \\
\hline Fatigue & $8.7(6.6)$ & $8.0(5.9)$ & ns & $12.0(8.1)$ & $-5.1^{* *}$ \\
\hline Confusion & $6.6(4.7)$ & $5.7(4.4)$ & $\mathrm{ns}$ & $13.0(6.7)$ & $-13.9^{* *}$ \\
\hline POMS Total & $25.1(37.2)$ & $17.7(33.0)$ & $2.1^{*}$ & 75.3 (not available) & $-13.9^{* *}$ \\
\hline
\end{tabular}

One-sample $t$ tests were used to determine significant differences between the SCI sample POMS scores and the POMS community and psychiatric norms $n s$ no significant difference, POMS Profile of Mood States, SCI spinal cord injury, SD standard deviation ${ }^{*} p<0.05{ }^{* *} p<0.01$ 
Table 2 POMS scores for the two SCI pain intensity sub-groups

\begin{tabular}{|c|c|c|c|c|c|c|c|}
\hline \multirow[t]{2}{*}{ POMS domains } & \multicolumn{2}{|c|}{ Low pain intensity $<4(n=51)$} & \multicolumn{2}{|c|}{ High pain intensity $\geq 4(n=56)$} & \multirow[t]{2}{*}{$F$ value } & \multicolumn{2}{|c|}{$\eta^{2}$ and $1-\beta(\%)$} \\
\hline & $\overline{\text { Mean }(S D)}$ & 95\% CI & $\overline{\text { Mean }(\mathrm{SD})}$ & $95 \% \mathrm{CI}$ & & & \\
\hline Tension & $4.9(4.8)$ & $3.6-6.3$ & $9.6(7.0)$ & $7.8-11.5$ & $16.1^{* *}$ & 0.13 & 98 \\
\hline Dep. mood & $7.1(9.5)$ & $4.4-9.7$ & $13.3(12.3)$ & $10.0-16.6$ & $8.5^{* *}$ & 0.07 & 82 \\
\hline Anger & $6.4(7.6)$ & $4.3-8.6$ & $10.8(9.3)$ & $8.3-13.3$ & $6.9^{*}$ & 0.06 & 74 \\
\hline Vigor & $18.0(5.6)$ & $16.4-19.6$ & $15.4(6.3)$ & $13.7-17.1$ & $5.0^{*}$ & 0.05 & 60 \\
\hline Fatigue & $6.4(5.1)$ & $4.9-7.8$ & $10.8(7.2)$ & $8.9-12.8$ & $13.4^{* *}$ & 0.11 & 95 \\
\hline Confusion & $5.1(4.2)$ & $4.0-6.3$ & $8.0(4.7)$ & $6.8-9.3$ & $10.8^{* *}$ & 0.09 & 90 \\
\hline POMS Total & $12.0(31.5)$ & $3.1-20.8$ & $37.1(38.2)$ & $26.8-47.3$ & $13.6^{* *}$ & 0.11 & 96 \\
\hline
\end{tabular}

ANOVA statistic, probabilities of difference, effect sizes $\left(\eta^{2}\right)$ and post hoc power $(1-\beta)$ are also shown Dep. mood Depressed mood

${ }^{*} p<0.05^{* *} p<0.01$

had substantially higher levels of negative mood states and reduced vigor. Table 2 also shows that these differences were associated with moderate to large statistical power, suggesting these differences are highly likely true findings.

\section{DISCUSSION}

A large proportion of the sample reported clinically significant levels of pain intensity. The high pain intensity sub-group (52\%) reported a mean score of $6 / 10 \quad(95 \%$ CI 5.4-6.5), and only $21.5 \%$ reported no pain on the day of assessment. These results are concerning and suggest that more attention should be given to addressing chronic pain in people with SCI. As an example, there is a growing evidence base and consensus for the efficacy of psychosocial approaches for the treatment of chronic pain, especially for people with SCI [18]. Examples include cognitive behavioral techniques to control pain-related catastrophizing, mindfulness techniques and activity pacing strategies [18].
Table 1 demonstrates that in comparison to POMS community norms, the SCI sample had significantly elevated depressed mood as well as reduced vigor and elevated total negative mood states. Importantly, however, the SCI sample had significantly lower levels of negative mood states and elevated vigor compared to psychiatric outpatient norms. This suggests that as shown by the low pain intensity subgroup, that many people with SCI are adjusting well to their impairments. As expected, the findings support an association between pain intensity and elevated depressed mood and anxiety. Additionally, pain intensity was also shown to be associated with elevated negative mood states such as anger, confusion, fatigue, as well as reduced vigor. These findings highlight the difficulties encountered by people with SCI who have intense chronic pain to deal with as well as any impairments associated with their injury. In contrast, the sub-group with low levels of pain intensity exhibited mood states similar to non-diseased male and female community norms [16]. While this research cannot clarify causal factors, the findings suggest that chronic intense pain seriously 
challenges the mental health status of adults with SCI.

Research has shown that chronic pain alone can have serious impacts on many aspects of life, including deterioration in sleep, work and participation in activities of daily living, and increased functional disability beyond that which results from loss of motor control [19]. The findings of this study highlight the need for rehabilitation therapies that can directly address the needs of those people with SCI who have clinically significant pain. Rehabilitation strategies are necessary to provide protection for people with SCI from the constant debilitating distress caused by intense and persistent pain. Latest research is providing some indication of direction in this regard [19-24].

Limitations of this study included lowered statistical power due to dichotomizing the sample into pain intensity sub-groups. However, effect sizes for group differences were moderate to large, and post hoc power estimates confirmed that the statistical power in the study was satisfactory so that the risk of a type II error rate was low [17]. Further, a crosssectional design was employed preventing the examination of causal factors. Prospective research should therefore be used to investigate causal relationships between chronic pain and mood states.

\section{CONCLUSION}

Intense chronic pain is associated with a range of negative mood states, and thus there is a critical need for research that evaluates the efficacy of rehabilitation therapies designed to improve self-management of chronic pain and consequent negative mood in adults with SCI. This is true for patients in inpatient hospital rehabilitation settings as well as those living in the community, and remains a challenge for future research in this area.

\section{ACKNOWLEDGMENTS}

We acknowledge the financial support of the Lifetime Care Support Authority (NSW, Australia), the Australian Research Council (LP0560590), and the Australian Rotary Health. Professor A. Craig is the guarantor for this article, and takes responsibility for the integrity of the work as a whole.

Conflict of interest. Ashley Craig, Dianah Rodrigues, Yvonne Tran, Nirupama Wijesuriya, Rebecca Guest and James Middleton declare no conflicts of interest.

Compliance with Ethics Guidelines. All procedures followed were in accordance with the ethical standards of the responsible committee on human experimentation (institutional and national) and with the Helsinki Declaration of 1975, as revised in 2000 and 2008. In formed consent was obtained from all patients included in the study. This article does not contain findings from treatment-based clinical intervention studies.

Open Access. This article is distributed under the terms of the Creative Commons Attribution Noncommercial License which permits any noncommercial use, distribution, and reproduction in any medium, provided the original author(s) and the source are credited.

\section{REFERENCES}

1. Sommer MF. Spinal cord injury. Functional rehabilitation. New Jersey: Prentice Hall; 2001. 
2. Middleton J, Tran Y, Craig A. Relationship between quality of life and self-efficacy in persons with spinal cord injuries. Arch Phys Med Rehabil. 2007;88:1643-8.

3. Westgren N, Levi R. Quality of life and traumatic spinal injury. Arch Phys Med Rehabil. 1998;79: 1433-9.

4. Bombardier $\mathrm{CH}$, Richards JS, Krause JS, Tulsky D. Symptoms of major depression in people with spinal cord injury: implications for screening. Arch Phys Med Rehabil. 2004;85:17-1756.

5. Haran MJ, Lee BB, King MT, Marial O, Stockler MR. Health status rated with the Medical Outcomes Study 36-Item Short-Form Health Survey after spinal cord injury. Arch Phys Med Rehabil. 2005;86:2290-5.

6. Craig A, Tran Y, Middleton J. Psychological morbidity and spinal cord injury: a systematic review. Spinal Cord. 2009;47:108-14.

7. Wijesuriya N, Tran Y, Middleton J, Craig A. The impact of fatigue on the health-related quality of life in persons with spinal cord injury. Arch Phys Med Rehabil. 2012;93:319-24.

8. Craig A, Tran Y, Wijesuriya N, Middleton J. Fatigue and tiredness in people with spinal cord injury. J Psychosom Res. 2012;73:205-10.

9. Jensen MP, Chodroff MJ, Dworkin RH. The impact of neuropathic pain on health-related quality of life. Review and implications. Neurology. 2007;68:1178-82.

10. Craig A, Tran Y, Siddall P, et al. Developing a model of associations between chronic pain, depressive mood, chronic fatigue and self-efficacy in people with spinal cord injury. J Pain. 2013;14:911-20.

11. Siddall PJ, McClelland JM, Rutkowski SB, Cousins MJ. A longitudinal study of the prevalence and characteristics of pain in the first 5 years following spinal cord injury. Pain. 2003;103:249-57.

12. Ullrich PM, Smith BM, Poggensee L, et al. Pain and post-traumatic stress disorder symptoms during inpatient rehabilitation among operation enduring freedom/operation Iraqi freedom veterans with spinal cord injury. Arch Phys Med Rehabil. 2013;94:80-5.

13. Widerstrom-Noga E, Biering-Sorensen F, Bryce T, et al. The international spinal cord injury pain basic data set. Spinal Cord. 2008;46:818-23.
14. Jensen MP, Turner JA, Romano JM, Fisher LD. Comparative reliability and validity of chronic pain intensity measures. Pain. 1999;83:157-62.

15. Forchheimer MB, Richards JS, Chiodo AE, Bryce TN, Dyson-Hudson TA. Cut point determination in the measurement of pain and its relationship to psychosocial and functional measures after traumatic spinal cord injury: a retrospective model spinal cord injury system analysis. Arch Phys Med Rehabil. 2011;92:419-24.

16. McNair DM, Lorr M, Droppleman LF. POMS. Profile of mood states manual. New York: Multi Health Systems Inc; 2005.

17. Cohen J. Statistical power analysis for the behavioral sciences. 2nd ed. New Jersey: LEA; 1988.

18. Jensen M. Psychosocial approaches to pain management: an organizational framework. Pain. 2011;152:717-25.

19. Norrbrink Budh C, Hultling C, Lundeberg T. Quality of sleep in individuals with spinal cord injury: a comparison between patients with and without pain. Spinal Cord. 2005;43:85-95.

20. Mehta S, Aubut JAL, Legassic M, et al. An evidencebased review of the effectiveness of cognitive behavioral therapy for psychosocial issues postspinal cord injury. Rehab Psychol. 2011;56:15-25.

21. Dorstyn D, Mathias J, Denson L. Efficacy of cognitive behavior therapy for the management of psychological outcomes following spinal cord injury. A meta-analysis. J Health Psychol. 2011;16:374-91.

22. Heutink M, Post MWM, Bongers-Janssen HMH, et al. The CONECSI trial: results of a randomized controlled trial of a multidisciplinary cognitive behavioral program for coping with chronic neuropathic pain after spinal cord injury. Pain. 2012;153:120-8

23. Norrbrink Budh C, Kowalski J, Lundeberg T. A comprehensive pain management programme comprising educational, cognitive and behavioural interventions for neuropathic pain following spinal cord injury. J Rehabil Med. 2006;38:172-80.

24. Charlifue S, Post MW, Biering-Sørensen F, et al. International spinal cord injury quality of life basic data set. Spinal Cord. 2012;50:672-5. 